\title{
OBSERVATIONS ON THE USE OF THIOURACIL IN RHEUMATOID ARTHRITIS
}

\author{
BY \\ KLAUS A. J. JÄRVINEN \\ From the Third Medical Clinic of the University of Helsinki, Finland
}

(RECEIVED FOR PUBLICATION OCTOBER 18, 1951)

No reports have been published on the possible effects upon rheumatoid arthritis of the thiouracil drugs, which have a potent action on the thyroid and also on the adrenal glands, although several investigators have pointed out certain correlations between disturbances of the thyroid on the one hand, and rheumatoid arthritis on the other, and the study of the adrenal cortex plays a central role in rheumatology. Tripi and others (1949) certainly observed in a careful investigation that rats treated with thiouracil developed a more severe experimental arthritis than control animals. However, these animal experiments are not directly applicable to human rheumatoid arthritis, particularly as the animals suffered from a septic arthritis quite different from the human disease. The rats were inoculated with a "pleuropneumonia-like organism"; in connection with the developing joint affections, abscesses were to be found in several organs, and the inoculated micro-organisms could be cultivated both from various organs and from the joints in pure culture.

The experimentation with thiouracil medication in cases of rheumatoid arthritis was initiated by a case in which thiouracil seemed to have a favourable action.

In 1947, a woman of 65 was admitted to our clinic, after having suffered for 7 years from rheumatoid arthritis and thyrotoxicosis which had appeared at about the same time and had progressed year by year. As the patient would not submit to an operation, which was recommended because of the severe symptoms of thyrotoxicosis, treatment with thiouracil was started in the ward. During this treatment, the symptoms of both thyrotoxicosis and rheumatoid arthritis disappeared simultaneously in the course of a month. The active swelling of the joints regressed, the articular pain disappeared, and the mobility of the joints recovered almost to normal. The erythrocyte sedimentation rate fell from 25 to $11 \mathrm{~mm}$., and the $\mathrm{Hb}$ value rose from 79 to 86 per cent. About six months after leaving the hospital the patient stopped the use of thiouracil; within less than a month the articular symptoms began to show signs of aggravation, but they recovered their previous condition when medication was resumed. After about a year, the patient again stopped the use of thiouracil; within 2 months the joint affections began to show an exacerbation, and, at the same time, the symptoms of thyrotoxicosis appeared in a more severe form than before. Medication with thiouracil, which was again given in the hospital, again had a favourable action on both diseases.

Since a recovery from the symptoms of rheumatoid arthritis was observed 
repeatedly in this present case during thiouracil medication, this drug has been tested on some other cases of rheumatoid arthritis.

\section{Material}

The material consists of ten cases of rheumatoid arthritis. One of these patients was suffering at the same time from manifest thyrotoxicosis, and two of the others exhibited slight symptoms suggestive of the latter disease. The remaining seven showed no signs of disturbance in thyroid function.

The patients were given methyl- or propyl-thiouracil, the amount varying between $7 \cdot 8$ and $51.6 \mathrm{~g}$. The duration of the treatment varied from 17 to 86 days. All the medication was carried out while the patients were in hospital.

The distribution of the material and the main results are shown in the Table (opposite).

As seen in the Table, distinct clinical improvement was observed during the treatment in eight out of the ten cases. (In one case, in which the thiouracil treatment was repeated after approximately two years, even this second course of medication was followed by a rapid recovery of the articular symptoms.) Five of the patients showed a rapid and marked improvement during the thiouracil treatment. In the three other cases, distinct improvement was also observed, but the recovery did not differ from those results which can be obtained in favourable cases with the aid of hospital treatment in general (excluding, of course, the rapid temporary disappearance of symptoms on administration of cortisone or ACTH). The clinical picture of two of the patients did not show any marked objective changes. Subjectively, the patients reported a slight reduction in pain. No aggravation of the symptoms was observed in any of the patients.

In analysing the improvement observed during the thiouracil medication, it has to be taken into account, of course, that these patients also received the usual general hospital treatment (rest in favourable hospital conditions, suitable nutrition, vitamins, etc.), and physical treatment and the usual anti-rheumatic drugs (salicylates against pain, etc.) were used. It must also be remembered that rheumatoid arthritis is a disease with a spontaneously fluctuating course. This makes an assessment of the efficacy of therapeutic measures difficult (for instance, opinions on the value of the gold treatment, which has been in use for years, are still at variance). However, after paying due attention to these factors, the improvement observed during the course of the thiouracil medication in the rather active symptoms of rheumatoid arthritis in the above five cases was still unusually pronounced. In four of these cases, the results must be given the greater significance as the patients had been suffering from their disease for 3-13 years, and several other methods of treatment had been tried, with rather meagre results. The fifth case was one of a patient in whom a rheumatic relapse had appeared in active form about a month before, and thus, the rapid recovery was not so spectacular as that seen in the other cases.

\section{Discussion}

Since the present results suggest that thiouracil may have a favourable action on the course of rheumatoid arthritis, the problem arises: what is the mechanism of this effect?

The best known effect of thiouracil, the reduction of the secretion of the thyroid (thiouracil is understood to inhibit the synthesis of thyroxin), can hardly play a marked role in rheumatoid arthritis. True, there are reports on a recovery from rheumatoid arthritis in connection with the operative or $x$-ray treatment of thyrotoxicosis from which the patient had been also suffering (Bauer and Camp, 1935; Curschmann, 1925; Deusch, 1922; Duncan, 1932; Viersma, 1936). 
TABLE

CHANGES IN SYMPTOMS OF RHEUMATOID ARTHRITIS (RA) DURING ADMINISTRATION OF THIOURACIL

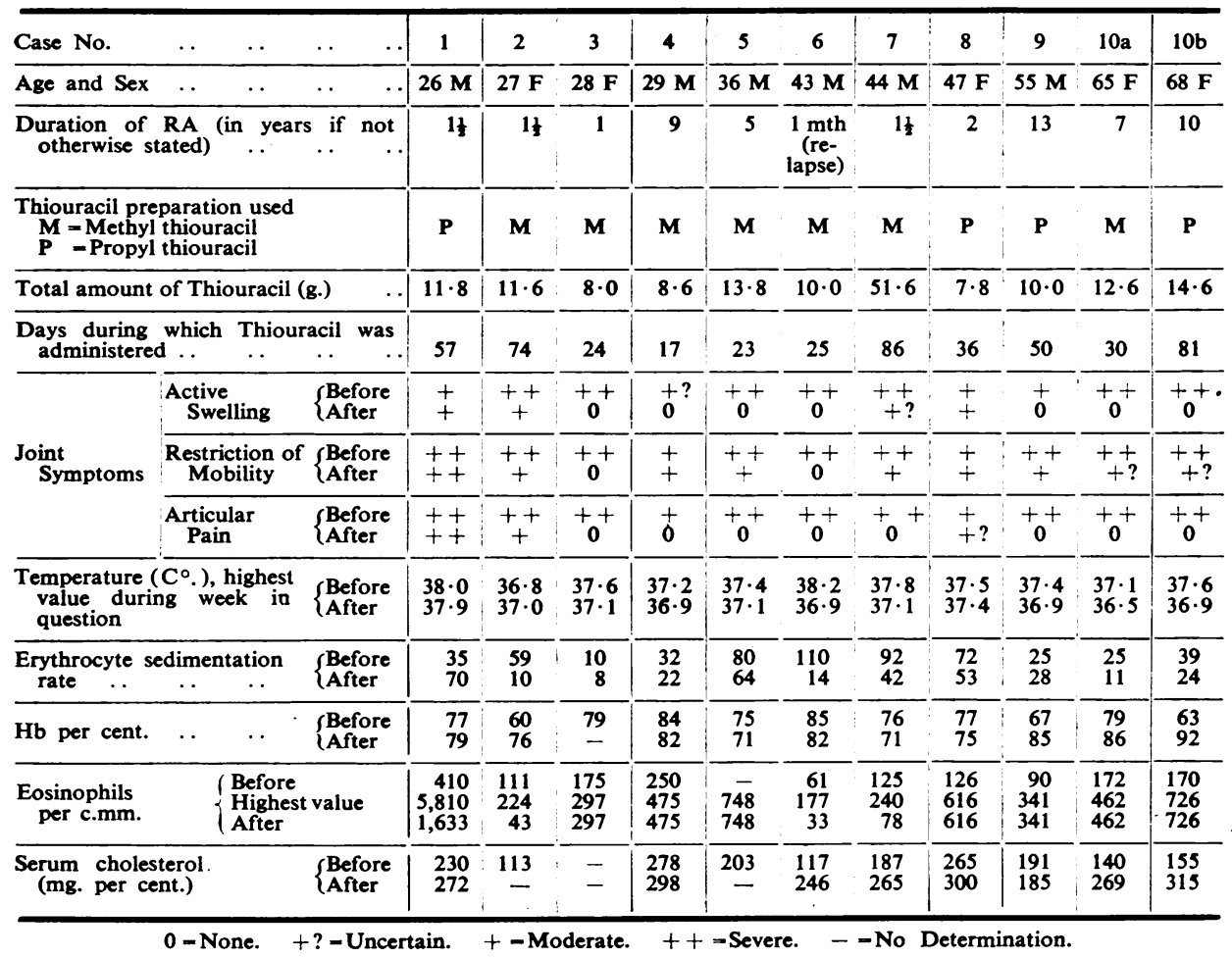

Additional Notes to TABle

Case 1. The patient had been in the ward continuously for 168 days before the propylthiouracil medication was started. He had been treated with myocrisin $270 \mathrm{mg}$. and blood transfusions $400 \mathrm{ml}$. $\times 4$ without any remission. He was still febrile. The sedimentation rate was 62 at the beginning and after the therapy $73 \mathrm{~mm}$. Then he was given cortone $2 \cdot 850 \mathrm{~g}$. during 23 days; the remission was moderate, and sedimentation rate fell from 75 to 19 . The second day after this therapy was stopped the articular pains became aggravated and the temperature rose. Seven days after stopping cortisone the thiouracil medication was started. After 2 weeks' thiouracil medication (propyl thiouracil $0.1 \times 3$ ) the patient was without fever, the sedimentation rate 54; the $\mathrm{Hb}$ per cent. had risen during this time from 77 to 85 . The patient himself found his joints as good as during the cortone therapy. As the number of the eosinophils per c.mm., however, had risen as high as to 5,810 , the daily amount of thiouracil had to be diminished, and only $0.1 \mathrm{~g}$. was given every second day. At this time a tonsillectomy was also performed; the RA symptoms were at once aggravated and the patient again became febrile.

Cases 2 and 6 . Both these patients had slight symptoms of thyrotoxicosis.

Case 10. In this case there was typical thyrotoxicosis (but no signs of exophthalmic goitre or struma nodosa).

However, observations showing quite contrary results have also been published. Rheumatoid arthritis has developed simultaneously with the symptoms of hypothyrosis after a resection of the thyroid (Cushing, 1937; Lundgren, 1943; Kirstein and Lövgren, 1937; Thomas, 1933). Correspondingly, different observations have been reported on the effects of thyroid medication upon the course 
of rheumatoid arthritis. For example, Hall and Monroe (1933) observed a favourable action in 16 per cent. and Rawls and others (1938) in 20 per cent. of their cases. Copeman (1946), on the other hand, found that thyroid medication can have disadvantageous reactions in severe rheumatoid arthritis.

The early inhomogeneous studies perhaps suggest the conclusion that a dysfunction of the thyroid, in one direction or another, may possibly facilitate an aggravation of rheumatoid arthritis. In any case, it is difficult to assume that thiouracil, through reducing the secretion of the thyroid, would have a favourable effect on rheumatoid arthritis. Seven of the patients were euthyrotic, and only one of them had a manifest thyrotoxicosis (two had slight but not definite symptoms).

Particular attention must be paid to the effects of thiouracil on the adrenal glands which play a central role in the problems of rheumatology. It has been demonstrated experimentally that the administration of thiouracil effects destruction and atrophy in the adrenal cortex (Arvy and Gabe, 1946; Deane and Greep, 1947; Florentin and others, 1947; Riker and Wescoe, 1945). Lesions have also been observed in the medulla (Arvy and Gabe, 1946). Clinical observations which confirm these experimental findings have also been reported. An inhibition of the eosinopenia which normally follows an injection of adrenalinewhich inhibition is regarded as a sign of the insufficiency of the adrenal cortexhas been observed to occur in patients in the course of thiouracil medication (de la Balze and others, 1951). The eosinophilia occurring in connection with thiouracil treatment may also be thought to depend on a hypofunction of the adrenal glands.

The results of several investigators, therefore, suggest that thiouracil medication reduces the hormone output of the adrenal cortex (and possibly also that of the medulla). Accordingly, the action of thiouracil would be deleterious in rheumatic disease, if the view often presented that factors which stimulate the function of adrenal cortex - as various forms of stress, etc.-act favourably on this disease. However, there are several facts which suggest that an active rheumatic state is connected, on the contrary, with a potent function of the adrenal cortex, whereas factors exerting a favourable action on rheumatoid arthritis are evidently connected with a suppressed function of the adrenal glands.

As is well known, Selye (1947) attributes a central role in the pathogenesis of rheumatic conditions to an increased excretion of mineralocorticoids as a consequence of various "stresses". It has also been clearly shown clinically that "stresses" stimulating adrenocortical function cause an exacerbation of the symptoms of rheumatoid arthritis. Thus, it has been demonstrated that cold, damp weather, mental and physical strain, as well as acute febrile infections (Järvinen, 1951) generally aggravate the clinical picture of rheumatoid arthritis and may serve as predisposing factors in its aetiology. This view is supported also by the finding that the active stage of rheumatoid arthritis is connected with eosinopenia (a sign of the stimulation of the adrenal function),-whereas the spontaneous recovery of the disease is evidently characterized by eosinophilia (Järvinen, 1950a).

As mentioned above, signs of reduced adrenal (adrenocortical) activity may, 
on the other hand, be demonstrated in connection with the rapid recovery of rheumatoid arthritis as effected by certain factors, such as severe jaundice, protracted starvation, toxic drug reactions, state of the organism after general anaesthesia, and massive administration of cortisone.

A severe jaundice - in general, the Meulengracht value has to rise to values like $1: 70-1: 90$ before a recovery from rheumatoid arthritis is effected, whether the jaundice is due to stone, tumour, or hepatocellular factors (Ahlberg, 1939; Lövgren, 1945) - is characterized by hypotonia, bradycardia, subnormal temperature, and a tendency to leucopenia, i.e. by symptoms indicating vagotonia, which suggests a reduced adrenal function. The same symptoms occur in protracted starvation which has also been observed to have a curative action on rheumatoid arthritis (Hench, 1949). The view that the adrenal function is suppressed in these conditions is supported also by histological changes in the adrenals of patients who have succumbed to starvation. These changes indicate an exhaustion (Klinge, 1949).

The symptoms of rheumatoid arthritis disappear rapidly in connection with some drug reactions of toxic character. This is observed most often during gold-salt treatment, but it has occurred also in connection with sulphonamides (Virkkunen, 1947) and cincophen (Rawls, 1939), and also with transfusion complications (Appelqvist and Holsti, 1947). The recovery of the joint symptoms is intimately connected with the development of hypotonia and eosinophilia, as is evident from studies made on gold-salt reactions (Järvinen, 1946). Again, these signs suggest rather an inhibition than a stimulation of the adrenal glands,

The effects of sulphonamides on the adrenal glands have also been studied experimentally, and several investigators have found that the adrenal glands of experimental animals are reduced in size during sulphonamide medication (Riker and Wescoe, 1945) as they are during the administration of thiouracil. A similar action on the endocrine system is also suggested by the fact that both of these compounds are strumogenic, both reduce the basal metabolic rate, and both raise the serum cholesterol level (as also does cortisone), which level has a tendency to fall in active rheumatoid arthritis. Some sulphonamide drugs-salazopyrin-have also given results of some value in the treatment of rheumatoid arthritis (Svartz, 1948).

The relief of the symptoms of rheumatoid arthritis, which is often observed after general anaesthesia and which lasts for a few days (Hench, 1949), may, according to the writer's view, be regarded as connected with an exhaustion of the adrenal cortex after the anaesthesia and not with a protracted hyperfunction.

The massive administration of cortisone which effects a rapid temporary cure of the symptoms of rheumatoid arthritis has been observed to produce atrophy of the adrenal cortex in experimental animals (Stebbins, 1950; Antopol and others, 1951; Nichols and Miller, 1949). This corresponds with the clinical observations in man of a decreased excretion of 17-ketosteroids during the massive administration of cortisone (Wilkins and others, 1951). This effect is possibly due to a reduction in the mineralocorticoid secretion and not to an extra supply of glucocorticoids (cortisone). An increase of the secretion of glucocorticoids, even to a pathophysiological extent, does not seem to have any curative effect on rheumatoid 
arthritis, nor even to be able to prevent its onset. This is suggested by work on the interrelations of rheumatoid arthritis and diabetes mellitus (Järvinen, 1950b).

The symptoms of rheumatoid arthritis do also sometimes disappear in connection with pregnancy. However, this phenomenon is by no means regular. For instance, there have been among the patients of our clinic during years 1934-1948 four women suffering from rheumatoid arthritis while pregnant in the fourth to the eighth month. In all of these, a temporary exacerbation of the disease occurred during pregnancy. (In eight women rheumatic fever began in the third to the ninth month, exhibiting articular symptoms, and in four the onset occurred just before delivery.) An assessment of the action of the different hormonal factors is rather difficult, as pregnancy produces thorough changes in the hormone equilibrium as a whole. It is possible that also the secretion of the adrenals varies individually and according to the stage of pregnancy.

\section{Conclusions}

Although the present cases of rheumatoid arthritis which were treated with thiouracil were closely observed, a definite assessment of the practical value of thiouracil in the treatment of patients suffering from rheumatoid arthritis cannot yet be made, on account of the paucity of the material. An estimate of the results is difficult because of the fluctuating character of the disease. However, the results were rather marked in some cases, and it is worthy of note that this treatment seems to have a mechanism of action-e.g. on the adrenal glands-similar to that of the most important agents acting favourably on rheumatoid arthritis.

\section{Summary}

Ten patients suffering from rheumatoid arthritis were given thiouracil in doses varying from $7 \cdot 8$ to $51 \cdot 6 \mathrm{~g}$. during a period of 17 to 86 days, under hospital control. In eight of the cases, a distinct improvement was observed during this treatment; in five of these the recovery was rather marked.

The discussion is chiefly devoted to the suppression of the functions of the adrenal glands (adrenal cortex) which was due to thiouracil medication, and to its possible role in the cures observed. Signs suggesting adrenocortical hypofunction are pointed out in connection with those conditions known to effect a rapid recovery from this disease, such as severe jaundice, protracted starvation, toxic drug reactions, general anaesthesia, and treatment with cortisone. Agents which bring about an increased function of the adrenal cortex are regarded as aggravating the symptoms of rheumatoid arthritis.

Ahlberg, G. (1939). Nord. Med., 3, 2430.

\section{REFERENCES}

Antopol, W., Glaubach, S., and Quittner, H. (1951). Rheumatism, 7 [January], 187.

Appelqvist, O., and Holsti, Ö. (1947). Schweiz. med. Wschr., 77, 977.

Arvy, L., and Gabe, M. (1946). C.R. Soc. Biol., Paris, 140, 945.

de la Balze, F. A., Mancini, R. C., Scarpa, C. J., and Arrillaga, F. C. (1951). J. clin. Endocrinol., $11,553$.

Bauer, W., and Camp, J. D. (1935). "Malacic Diseases of Bone." In "Nelson's New Loose-leaf Surgery", 175,N. Nelson, New York.

Copeman, W. S. C. (1946). "The Treatment of Rheumatism in General Practice", 4th ed. . Arnold, London.

Curschmann, H. (1925). Dtsch. Z. Chir., 192, 13.

Cushing, E. H. (1937). Int. Clin., 47 ser., 2, 200.

Deane, H. W., and Greep, R. O. (1947). Endocrinology, 41, 243. 
Deusch, G. (1922). Klin. Wschr., 1, 2226.

Duncan, W. S. (1932). J. Amer. med. Ass., 99, 1239.

Florentin, R., Martin, R., and Sadoul, P. (1947). C.R. Soc. Biol., Paris, 141, 177.

Hall, F. C., and Monroe, R. T. (1933). J. Lab. clin. Med., 18, 439.

Hench, P. S. (1949). Annals of the Rheumatic Diseases, 8, 90.

Järvinen, K. A. J. (1946). Duodecim (Helsinki), 62, 1006.

- (1950a). Ann. Med. intern. fenn., 39, Suppl. 5.

- (1950b). Annals of the Rheumatic Diseases, 9, 226.

(1951). Rheumatism, 7 [July], 33.

Kirstein, L., and Lövgren, O. (1937). Svenska Läkartidn., 34, 1819.

Klinge, F. (1949). Zbl. allg. Path. path. Anat., 85, 325.

Lundgren, N. R. (1943). Nord. Med., 20, 2007.

Lövgren, O. (1945). Acta med. scand., Suppl. 163.

Nichols, J., and Miller, A. T. (1949). Proc. Soc. exp. Biol., N. Y., 70, 300.

Rawls, W. B. (1939). J. Amer. med. Ass., 112, 2509.

—- Ressa, A. A., Gruskin, B., and Gordon, A. S. (1938). Ann. intern. Med., 11, 1401.

Riker, W. F., and Wescoe, W. C. (1945). Amer. J. med. Sci., 210, 665.

Selye, H. (1947). " Textbook of Endocrinology." Acta Endocrinologica, Montreal.

Stebbins, R. B. (1950). Fed. Proc., 9, 345.

Svartz, N. (1948). Nord. Med., 37, 299.

Thomas, H. M. (1933). Arch. intern. Med., 51, 571.

Tripi, H. B., Kuzell, W. C., and Gardner, G. M. (1949). Annals of the Rheumatic Diseases, 8, 125.

Viersma, H. J. (1936). Z. klin. Med., 130, 660.

Virkkunen, M. (1947). Ann. Med. intern. fenn., 36, 198.

Wilkins, L., Lewis, R. A., Klein, R., Gardner, L. I., Crigle, J. F., Rosemberg, E., and Migeon, C. J. (1951). J. clin. Endocrinol., 11, 1.

\section{L'emploi du thiouracil dans l'arthrite rhumatismale \\ RéSUMÉ}

Dix malades atteints d'arthrite rhumatismale furent traités par thiouracil en doses variant de 7,8 à 51,6 g. pendant des périodes de 17 à 86 jours, sous le contrôle hospitalier. Au cours de ce traitement on nota une amélioration appréciable dans huit cas et dans cinq d'entre eux le rétablissement fut assez marqué.

On discute surtout la suppression de la fonction cortico-surrénale à la suite de la médication par le thiouracil et on considère son rôle dans les guérisons observées. On signale les manifestations qui suggèrent une diminution de la fonction cortico-surrénale, ce qu'on interprète à la lumière des facteurs qu'on sait capables d'effecteur un rétablissement rapide, tels qu'ictère grave, famine prolongée, réactions toxiques aux substances médicamenteuses, anesthésie générale et traitement par la cortisone. Les agents susceptibles d'augmenter la fonction de l'écorce surrénale sont considérés capables d'aggraver les symptomes de l'arthrite rhumatismale.

\section{El empleo de tiouracil en la al tritis reumatoide SUMARIO}

Diez enfermos con artritis reumatoide fueron tratados con tiouracil cuya dosis variaba de 7,8 a 51,6 g. durante períodos de 17 a 86 días, bajo control hospitalario. Durante el tratamiento se notó en ocho casos una mejoría distinta, bastante pronunciada en cinco de ellos.

El objeto principal de la discusión es la función córtico-suprarrenal que queda suprimida a consecuencia de la medicación con tiouracil, así como el papel de éste en las curaciones observadas. Se señala las manifestaciones que sugieren una diminición de la función córtico-suprarrenal en relación con los factores que se sabe capaces de producir el restablecimiento del enfermo, como ictericia grave, inanición prolongada, reacciones medicamentosas tóxicas, anestesia general y tratamiento con la cortisona. Se considera que los factores que hacen aumentar la función de la corteza suprarrenal también agravan los sintomas de la artritis reumatoide. 